\title{
O DESFLORESTAMENTO E SUAS RELAÇÕES COM AS LEGISLAÇÕES FEDERAIS: UMA ANÁLISE SOBRE OS ASSENTAMENTOS RURAIS DO MUNICÍPIO DE MANICORÉ/AM
}

\author{
Matheus Lucas Maciel Leal ${ }^{1}$ \\ Vanderlei Maniesi ${ }^{2}$
}

\begin{abstract}
Resumo: A presente pesquisa objetivou quantificar o desflorestamento dentro dos assentamentos rurais inseridos no município de Manicoré/AM no período de 2000 a 2014, bem como comparar seu comportamento com o surgimento das principais legislações ambientais que visam sua mitigação. Para obtenção dos dados foram necessários procedimentos de geoprocessamento com o uso de software específico ArcGis 10.3, além do levantamento bibliográfico permitiu identificar as principais políticas agrárias que surgiram a partir dos anos 2000. Os resultados mostraram que os assentamentos rurais estudados exibem uma taxa de desflorestamento média de 1.199 ha.ano ${ }^{-1}$ no período delineado, representando $26,3 \%$ do desflorestamento que ocorre no município de Manicoré/AM. A partir da análise dos dados pode-se constatar que a instituição de legislações federais reflete na redução imediata do desflorestamento no ano seguinte que, no entanto, não apresentava continuidade neste padrão. Ainda assim, é possível identificar a forte influência dos programas de governo na dinâmica de desflorestamento.
\end{abstract}

Palavras-chave: assentamentos rurais; legislação; geoprocessamento; sustentabilidade; Amazonas.

\section{THE DEFORESTATION AND ITS RELATIONS WITH THE FEDERAL LEGISLATION: AN ANALYSIS UPON THE RURAL SETTLEMENTS IN THE MUNICIPALITY OF MANICORÉ/AM}

\begin{abstract}
This paper aimed to quantify the deforestation levels inside the rural settlements in the municipality of Manicoré (Brazil) from 2000 to 2014, and compare these behaviors with the releasing of the main environmental protection laws that aimed its mitigation. To get the data, geoprocessing procedures were necessary through the use of the specific software ArcGis 10.3, besides the bibliographical research that identified the main agrarian policies which appeared after 2000 . The results demonstrated that the rural settlements under study showed an average deforestation rate of 1.99 ha.year $^{-1}$ in the above period, representing $26,3 \%$ of the deforestation that occurred in the municipality of Manicoré. From the data analysis, we concluded that the federal legislation reflected an immediate reduction over the
\end{abstract}

\footnotetext{
${ }^{1}$ Fundação Universidade Federal do Amazonas. Iucax.leal@gmail.com

${ }^{2}$ Professor Associado da Universidade Federal de Rondônia. maniesi@unir.br
} 
deforestation after that, which, however, did not continue in the same patterns afterwards. Thus, we can clearly identify the strong influence of the government programs upon the dynamics of the deforestation.

Keywords: Rural Settlements; Environmental Legislation; Geoprocessing. Sustainability. Amazonas;

\section{INTRODUÇÃO}

A colonização da Amazônia foi facilitada pela criação de eixos de desenvolvimento (rodovias) onde foram implantados assentamentos de reforma agrária os quais, comumente, são apontados como um dos vetores do desflorestamento na região amazônica. De acordo com estimativas do Instituto do Homem e Meio Ambiente da Amazônia - IMAZON (FONSECA et al., 2016), em janeiro de 2016 constatou-se que 76\% do desflorestamento da Amazônia Legal ocorreram em áreas privadas. Entretanto, na mesma época, verificou-se que $12 \%$ são de responsabilidade de assentamentos de reforma agrária, valor semelhante ao mensurado em 2004 por Brandão Júnior e Souza Júnior (2006), onde os assentamentos representavam $15 \%$ do desflorestamento na região amazônica.

Além da acessibilidade, facilitada por intermédio das rodovias (BR 319 e BR 230 - Transamazônica), o desflorestamento na porção sul do Amazonas é explicado, também, pela presença desses projetos de assentamentos do INCRA. Vetores econômicos como o crescimento da pecuária e extração de madeira nas regiões de fronteira (Boca do Acre, Canutama e Lábrea) e a facilidade da expansão de cultura de soja nas áreas de campos naturais (Humaitá, Manicoré, Canutama e Lábrea) são outras variáveis que explicam a expansão de fronteira para esta região (AMAZONAS, 2008).

A reforma agrária no estado do Amazonas é mais efetiva na porção sul com a presença de grandes projetos de assentamentos tradicionais (PA), como Acari (Novo Aripuanã), Juma (Apuí) e Matupi (Manicoré). Atualmente, este é um dos estados mais comtemplados com a implantação de modalidades extrativistas (Projeto de Assentamento Agroextrativista - PAE, Projeto de Desenvolvimento Sustentável - PDS e Projeto de Assentamento Florestal - PAF). O município de Manicoré é um exemplo, apresentando em sua composição agrária tanto a modalidade convencional (PA Matupi) como Projetos de Assentamentos Agroextrativistas - PAEs (Baetas, Fortaleza, Jenipapos, Lago do Acará, Matupiri e Onças), INCRA (2014).

Buscando a contenção do desflorestamento na Amazônia Legal o governo passou a utilizar instrumentos legislativos que tinham como estratégica a punição para o uso predatório da floresta. Para Oliveira (2016) a criação da Política Nacional do Meio Ambiente (Lei $n^{\circ} 6.938 / 81$; BRASIL, 1981) ainda na década de 1980, foi um marco na criação de órgãos ambientais de âmbito federal, pois foi a partir dela que surgiram órgãos ambientais como o Sistema Nacional de Meio Ambiente SISNAMA que é constituído dos órgãos: Conselho Nacional do Meio Ambiente CONAMA, Instituto Brasileiro do Meio Ambiente e dos Recursos Naturais Renováveis - IBAMA e o Instituto Chico Mendes de Biodiversidade - ICMbio.

O histórico da intersecção entre a política agrária e a política ambiental é recente, com início ainda na primeira década de 2000. A criação da resolução 289 do Conselho Nacional do Meio Ambiente - CONAMA (BRASIL, 2001), representou o ponto de partida no que se refere à criação de instrumentos políticos/ambientais 
para as áreas de assentamentos rurais (OLIVEIRA, 2016). Esta resolução estabelece diretrizes para o licenciamento ambiental em áreas de assentamentos rurais, bem como medidas de controle para seu desflorestamento (BRASIL, 2001), mostrando a preocupação governamental com a inserção da gestão ambiental nestas áreas.

Não sendo necessariamente direcionado à contenção do desflorestamento em áreas de assentamentos rurais, em 2004 foi lançado o plano de ação para prevenção do desmatamento na Amazônia Legal - PPCDAm que assinala em um de seus objetivos específicos a redução do desflorestamento em assentamentos rurais através do ordenamento territorial (BRASIL, 2004).

Em seguida foram tomadas duas medidas: a alteração do Código Florestal e a instituição de Projetos de Assentamentos Verdes - PAV. As alterações do Código Florestal através da Lei $n^{\circ} 12.651$ (BRASIL, 2012a) reflete nos assentamentos rurais, pois menciona sobre a manutenção de $80 \%$ de áreas de floresta em áreas de reserva legal. O PAV, por sua vez, consiste num programa de governo que disponibiliza crédito para redução do desflorestamento nestas áreas (BRASIL, 2012b).

O Código Florestal é considerado como a principal legislação florestal brasileira (CASTELO, 2015), regimentando sobre a conservação de áreas de Reserva Legal (BRASIL, 2012a). O estudo de Streck e Essi (2013) mostra que para o caso dos assentamentos rurais, é necessário um investimento em programas de educação ambiental para facilitar a conversa entre a comunidade científica e os assentados que ainda relacionam a conservação com déficit na sua produção. Atualmente a resolução CONAMA n 458 (BRASIL, 2013a) que consiste na última versão da CONAMA n 289 (BRASIL, 2001) tornou-se a medida mais recente da política agrária.

Neste contexto, a presente pesquisa teve por objetivo quantificar o desflorestamento dentro dos assentamentos rurais do município de Manicoré, no período de 2000 a 2014 e identificar suas relações com as principais legislações ambientais que visam sua mitigação.

\section{MATERIAIS E MÉTODOS}

\section{ÁREA DE ESTUDO}

A área de estudo consiste em sete Projetos de Assentamentos Agroextrativistas - PAEs e um Projeto de Assentamento Federal - PA (Tabela 1), os quais, juntos, abrangem uma área de 276.244,2 hectares (Tabela 2) e estão situados no município de Manicoré, sul do Amazonas (Figura 1).

Tabela 1 - Relação dos Projetos de Assentamentos Agroextrativistas (PAEs) e Projeto de Assentamento Federal (PA) localizados em Manicoré/AM.

\begin{tabular}{l|c|c|c|c}
\hline \multicolumn{1}{c|}{ Nome do Projeto } & Área**(ha) & $\begin{array}{c}\text { Capacidade } \\
\text { (Famílias) }^{*}\end{array}$ & $\begin{array}{c}\text { Assentados } \\
\text { (Famílias) }^{*}\end{array}$ & Criação* \\
\hline PA Matupi & $34.941,0$ & 533 & 372 & 1992 \\
PAE Baetas & $38.463,2$ & 100 & 45 & 2010 \\
PAE Fortaleza & $26.906,1$ & 100 & 49 & 2010 \\
PAE Jenipapos & $48.548,1$ & 395 & 372 & 2004 \\
PAE Lago do Acará & $108.215,5$ & 150 & 42 & 2011 \\
PAE Matupiri & $9.710,1$ & 70 & 70 & 2001 \\
\hline
\end{tabular}




\begin{tabular}{|l|l|l|l|l|}
\hline PAE Onças & $9.460,3$ & 440 & 327 & 2006 \\
\hline
\end{tabular}

Base de dados: INCRA, 2014*; INCRA, 2016**.
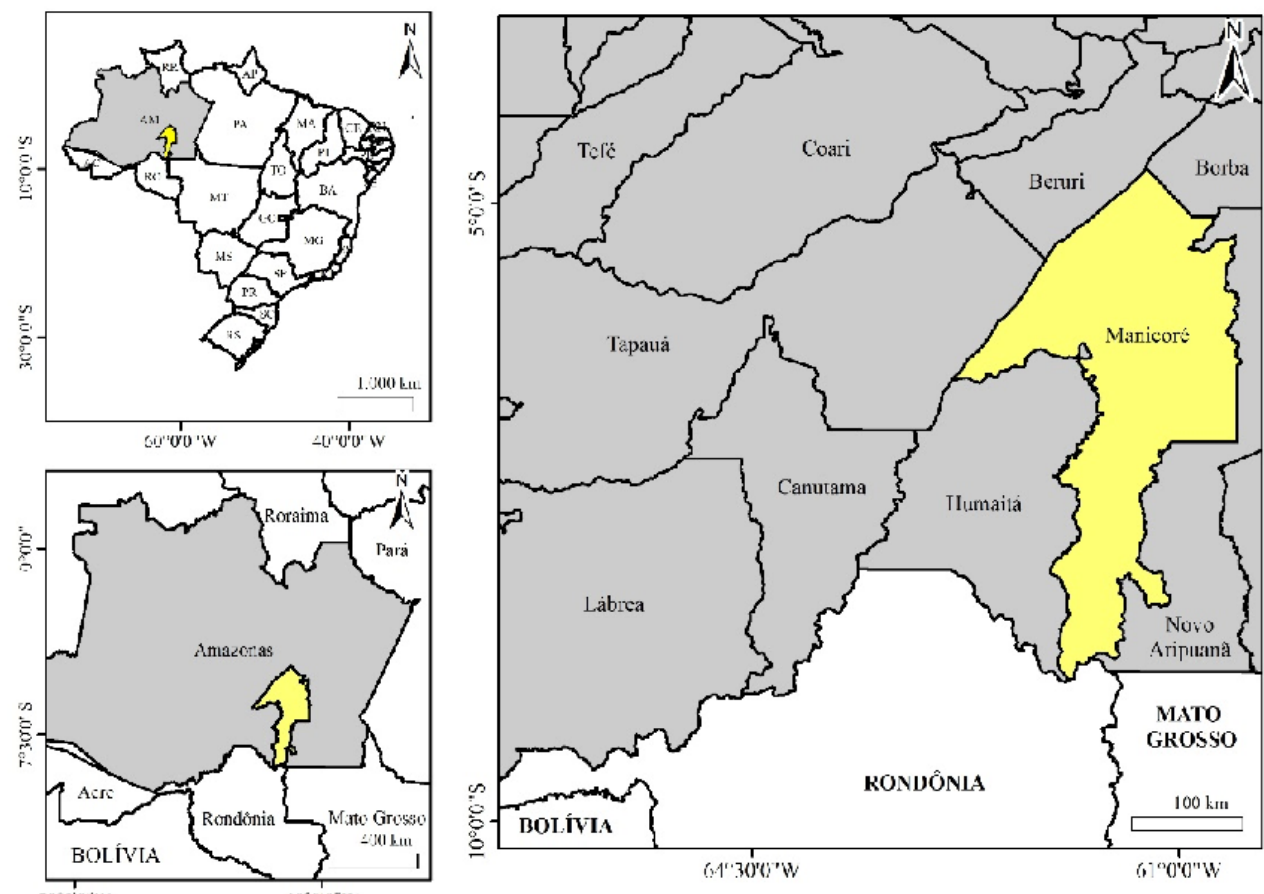

Figura 1 - Localização do município de Manicoré/AM.

Os assentamentos rurais do município de Manicoré foram criados oficialmente no período de 1992 (PA Matupi) a 2010 (PAE Baetas e Fortaleza), abrangendo uma área de 39.500 ha com capacidade para 1.788 famílias. Segundo INCRA (2014), atualmente estão classificados como fases 3 (Assentamento criado), 4 (Assentamento em instalação) e 5 (Assentamento em estruturação). Os projetos estudados representam, aproximadamente, $78 \%$ do total implantando no município de Manicoré, contendo $72,7 \%$ de suas famílias assentadas e representando $34,7 \%$ da área destinada à reforma agrária no município (Tabela 2).

Tabela 2 - Dados amostrais dos assentamentos rurais do município de Manicoré/AM.

\begin{tabular}{l|c|c|c|c|c|c}
\hline \multirow{2}{*}{ Amostra } & \multicolumn{2}{|c|}{ Assentamentos } & \multicolumn{2}{c|}{ Área** (ha) } & \multicolumn{2}{c}{ Famílias* $^{*}$} \\
\cline { 2 - 7 } & Total & $\%$ & Total & $\%$ & Total & $\%$ \\
\hline Manicoré & 9 & 100 & $796.499,2$ & 100 & 1.756 & 100 \\
Assentamentos estudados & 7 & 77,8 & $276.244,2$ & 34,7 & 1.277 & 72,7 \\
\hline
\end{tabular}

Base de dados: INCRA, 2014*; INCRA, 2016**.

\section{BANCO DE DADOS}

Para obtenção dos resultados foi elaborado um banco de dados de Sistema de Informação Geográfica - SIG a partir de informações digitais vetoriais (shapefiles) dos assentamentos de reforma agrária, disponível no website do Instituto Nacional de Colonização e Reforma Agrária - INCRA (INCRA, 2016) e dados de desflorestamento mensurado pelo projeto Programa de Cálculo do Desflorestamento da Amazônia Digital - PRODES, obtidos na plataforma digital do Instituto Nacional 
de Pesquisas Espaciais - INPE (INPE, 2003, com atualização permanente). Os dados de desflorestamento, em escala municipal, também foram compilados diretamente da base de dados do projeto PRODES digital, os quais foram utilizados para a estimativa da participação percentual dos assentamentos rurais no desflorestamento do município de Manicoré.

\section{GEOPROCESSAMENTO}

O método aplicado consistiu na aplicação de procedimentos de geoprocessamento a partir do cruzamento de informações de reforma agrária (INCRA, 2016) com dados de desflorestamento (INPE, 2003, com atualização permanente) utilizando o software específico de Sistema de Informação Geográfica - SIG ArcGis 10.3.

\section{CRIAÇÃO DE UM ARQUIVO VETORIAL SHAPEFILE PARA CADA ASSENTAMENTO}

Uma vez obtidos os limites digitais (shapefiles) dos assentamentos rurais do município de Manicoré, foi criado um arquivo único para cada assentamento estudado, com intuito de identificar o desflorestamento nas diferentes áreas. Para o download dos shapefiles de desflorestamento do PRODES digital correspondente ao ano de 2014, foram utilizadas as órbitas-ponto apresentadas na Tabela 3.

Tabela 3 - Relação de Projetos de Assentamentos Agroextrativistas (PAEs) e Projeto de Assentamento Federal (PA) do município de Manicoré/AM e suas respectivas órbitas-ponto.

\begin{tabular}{l|c}
\hline \multicolumn{1}{c|}{ Nome do Projeto } & Órbitas-ponto \\
\hline PA Matupi & $231 / 65$ \\
PAE Baetas & $232 / 64$ \\
PAE Fortaleza & $231 / 64$ e $232 / 64$ \\
PAE Jenipapos & $231 / 64$ \\
PAE Lago do Acará & $232 / 64$ \\
PAE Matupiri & $231 / 64$ \\
PAE Onças & $231 / 64$ \\
\hline
\end{tabular}

\section{PROJEÇÃO, SOBREPOSIÇÃO, RECORTE E CÁLCULO DE ÁREA}

Com auxílio do ArcGis 10.3, os arquivos digitais vetoriais (shapefiles) foram ajustados à projeção Universal Transversa de Mercator (UTM), Zona 20S, e datum SIRGAS 2000. Posteriormente, e ainda em ambiente SIG, os arquivos shapefiles de reforma agrária (INCRA, 2016) e desflorestamento (INPE, 2003, com atualização permanente) foram sobrepostos e recortados com intuito de obter a dimensão quantitativa do desflorestamento dentro dos assentamentos. Após o recorte houve o cálculo de área, em hectares, dos PAEs e PA do município de Manicoré no período de 2000 a 2014.

Tendo como referência estes dados, foi elaborado um mapa com intuito de expressar o percentual de uso e cobertura do solo nos Projetos de Assentamentos Agroextrativistas - PAEs e no Projeto de Assentamento Federal (PA) do município de Manicoré. Estes valores foram agrupados nos intervalos de 0 a $5 \%, 5$ a $15 \%$ e 
acima de $50 \%$. As classes quantificadas foram: desflorestamento até 2014 , floresta, hidrografia e não floresta natural.

Uma vez conhecido os valores das taxas anuais em escala municipal e dentro dos assentamentos, pôde-se estimar a participação percentual dos projetos no desflorestamento de Manicoré.

A etapa final da pesquisa consistiu em análise bibliográfica visando identificar as legislações e programas de mitigação do desflorestamento correspondentes ao período de análise. A partir disto, foi efetuada uma comparação do comportamento dos assentamentos de reforma agrária do município de Manicoré ao longo do período de vigência das legislações: resolução CONAMA nº 289 (BRASIL, 2001), Plano de ação para a prevenção e controle do desflorestamento na Amazônia Legal - PPCDAm (BRASIL, 2004), Código Florestal (BRASIL, 2012a), Programa Assentamentos Verdes - PAV (BRASIL, 2012b) e Resolução CONAMA n 458 (BRASIL, 2013a).

\section{RESULTADOS E DISCUSSÃO}

\section{DIAGNÓSTICO DO DESFLORESTAMENTO NO MUNICÍPIO DE MANICORÉ/AM}

O incremento do desflorestamento no município de Manicoré, no período de 2000 a 2014, apresentou um comportamento oscilatório, exibindo uma área de desflorestamento média igual a 5.450 ha, com valor máximo de 10.360 ha atingido em 2004 (Figura 2). Em 2014, Manicoré esteve entre os três municípios mais desflorestados no estado do Amazonas (Tabela 4), ainda que suas taxas de desflorestamento apresentem proporções menores desde 2004.

Figura 2 - Taxas anuais de desflorestamento em hectares no município de Manicoré, AM no período de 2000 a 2014.

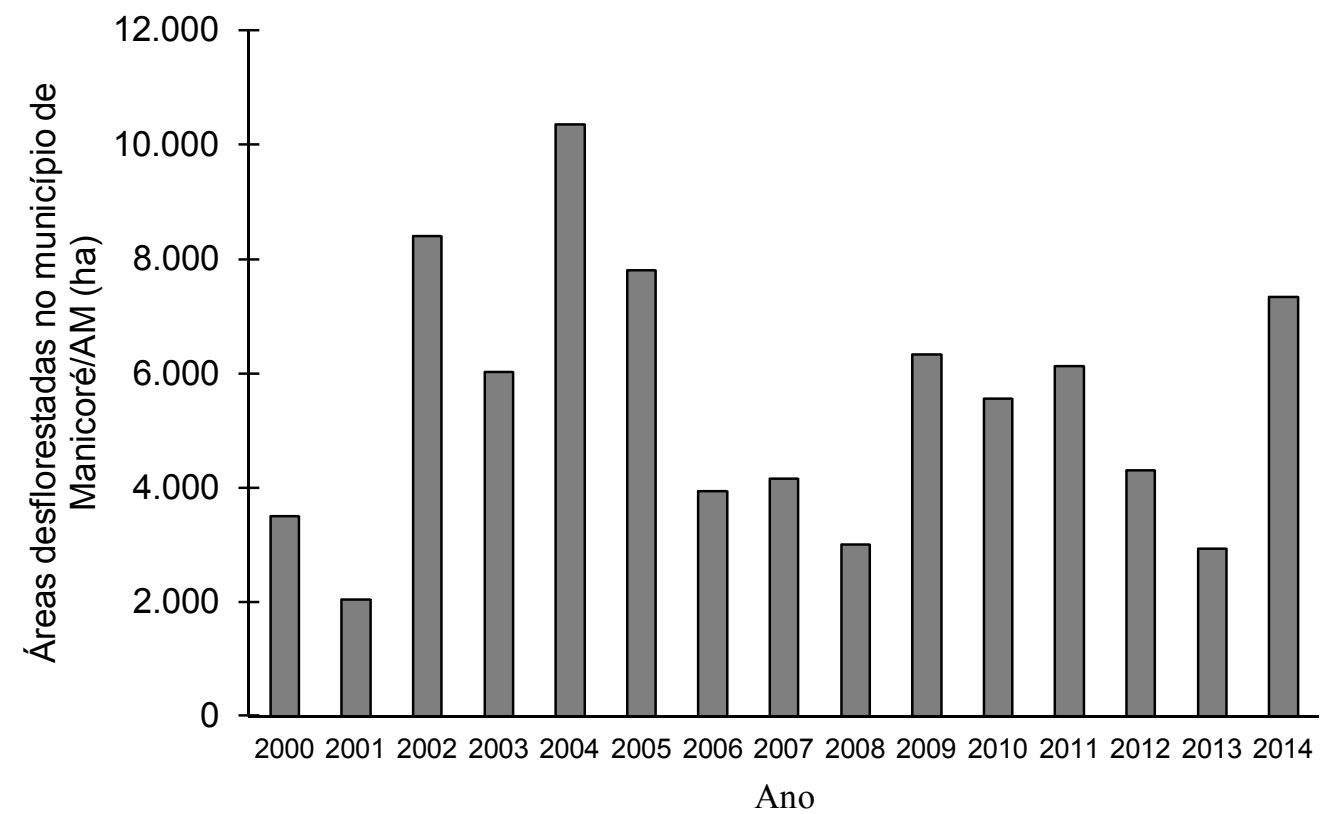

Base de dados: INPE (2003), com atualização permanente. 
Tabela 4 - Ranking de desflorestamento nos municípios do estado do Amazonas, $2014 / 2015$.

\begin{tabular}{c|c}
\hline Município & $\begin{array}{c}\text { Incremento } \\
\text { desflorestamento (ha) }\end{array}$ \\
\hline Lábrea & 24.260 \\
Apuí & 10.720 \\
Manicoré & $\mathbf{7 . 3 4 0}$ \\
Novo Aripuanã & 5.340 \\
Boca do Acre & 4.450 \\
\hline
\end{tabular}

Base de dados: INPE (2003), com atualização permanente.

O Produto Interno Bruto (PIB) é um fator em comum entre os municípios do Amazonas com as maiores taxas de desflorestamento. Este mostra que suas economias são embasadas principalmente na agropecuária (Tabela 5), considerada como uma das responsáveis pelo desflorestamento da região amazônica quando realizada de forma intensiva (ALENCAR et al., 2004). As fazendas de grande porte, onde é comum a prática da pecuária, representam $70 \%$ das atividades de desflorestamento (FEARNSIDE, 2005).

Tabela 5 - Configuração do Produto Interno Bruto (PIB) dos municípios mais desflorestados no Amazonas.

Fonte: IBGE, 2017.

\begin{tabular}{c|c|c|c}
\hline Município/PIB & Agropecuária & Indústria & $\begin{array}{c}\text { Outros } \\
\text { Serviços }^{*}\end{array}$ \\
\hline Lábrea & 155.150 & 12.765 & 45.980 \\
Apuí & 69.915 & 11.460 & 32.843 \\
Manicoré & $\mathbf{1 7 1 . 0 9 5}$ & $\mathbf{2 5 . 8 2 4}$ & $\mathbf{7 0 . 3 4 6}$ \\
Novo Aripuanã & 38.929 & 7.745 & 17.238 \\
Boca do Acre & 55.826 & 27.335 & 56.996 \\
\hline
\end{tabular}

*Administração, saúde e educação pública e seguridade social.

Além da possível influência econômica, o desflorestamento do município de Manicoré pode ter relação com a rodovia Transamazônica (BR 230) que liga seu projeto de assentamento rural mais antigo, PA Matupi, a sede do município adjacente, Humaitá (180 km), favorecendo a migração que muitas vezes é acompanhada da ocupação ilegal. Silva (2012) relata sobre o desflorestamento em vicinais no PA Matupi que não foram ocupadas oficialmente.

\section{DESFLORESTAMENTO NOS PROJETOS DE ASSENTAMENTOS AGROEXTRATIVISTAS (PAES) E NO PROJETO DE ASSENTAMENTO FEDERAL (PA) DO MUNICÍPIO DE MANICORÉ/AM}

A área de cobertura florestal até o ano de 2014 ainda é predominância nos Projetos de Assentamentos Agroextrativistas - PAEs do município de Manicoré (68,6\%, aproximadamente). Essa dinâmica de área ocorre devido aos projetos serem criados recentemente (Tabela 1) com objetivo de desenvolver atividades pouco impactantes (extrativistas). Alencar et al. (2016) assinala que os assentamentos criados nos últimos 17 anos possuem taxas de desflorestamento inferiores a $1 \%$. 
Em contrapartida, o Projeto de Assentamento Federal (PA) Matupi, apresenta 18.879,6 ha de desflorestamento, superior à sua área de floresta (Tabela 6). No entanto, a própria legislação do Instituto Nacional de Colonização e Reforma Agrária - INCRA, no mesmo ano de criação deste projeto, em 1992, através da Instrução Normativa $n^{\circ} 3$ de 8 de setembro, estabelecia sobre a desapropriação de florestas nativas com ausência de produção. Se por um lado esta instrução normativa pode ser considerada como incentivo à produção dentro dos assentamentos de reforma agrária, por outro pode ser vista como uma medida de estímulo ao desflorestamento nestas áreas.

Tabela 6 - Desflorestamento, em hectares, nos Projetos de Assentamentos Agroextrativistas (PAEs) e Projeto de Assentamento Federal (PA) do município de Manicoré/AM.

\begin{tabular}{l|c|c|c|c}
\hline $\begin{array}{c}\text { Projeto/Classe } \\
\text { (ha) }\end{array}$ & $\begin{array}{c}\text { Desfloresta- } \\
\text { mento até } \\
\mathbf{2 0 1 4}\end{array}$ & Floresta & $\begin{array}{c}\text { Hidrogra- } \\
\text { fia }\end{array}$ & $\begin{array}{c}\text { Não } \\
\text { floresta } \\
\text { natural }\end{array}$ \\
\hline PA Matupi & $18.879,6$ & $15.802,9$ & 0,0 & 0,0 \\
PAE Baetas & $2.626,1$ & $31.301,9$ & 730,4 & $1.059,8$ \\
PAE Fortaleza & 914,61 & $14.203,4$ & 194,2 & 459,2 \\
PAE Jenipapos & $5.584,9$ & $41.194,0$ & 412,4 & $1.042,3$ \\
PAE Lago do & $1.274,6$ & $99.958,3$ & 629,9 & $1.109,3$ \\
Acará & 351,1 & $7.789,1$ & 27,4 & $1.315,7$ \\
PAE Matupiri & 93,1 & $4.096,5$ & 457,1 & $4.786,0$ \\
PAE Onças & $4.246,29$ & $30.620,8$ & 350,20 & $1.396,04$ \\
Média &
\end{tabular}

Base de dados: INPE (2003), com atualização permanente.

Além de apresentarem objetivos extrativistas e de baixo impacto ambiental os PAEs Baetas, Fortaleza, Jenipapos, Lago do Acará, Matupiri e Onças, não apresentam influência de rodovias em sua dinâmica de transporte já que o acesso a estes projetos é realizado por meio fluvial, fatores que possivelmente explicam a extensão da área de floresta nestes projetos. No ano de 2000 , os assentamentos rurais do município de Manicoré, exibem sua área desflorestada máxima, atingindo $3.582,7$ ha, que correspondem a $1,3 \%$ da área destinada à reforma agrária do município (Figura 3).

No período de 2000 a 2001 houve tendência de redução nos valores de desflorestamento nos assentamentos rurais do município de Manicoré os quais, a partir daí, começaram a oscilar entre 159,2 a $1.654,8$ ha $O$ dado mais recente mostra que o desflorestamento nos assentamentos rurais do município de Manicoré corresponde a $0,3 \%$ da área destinada a reforma agrária do município. No que se refere a sua participação no desflorestamento do município, os assentamentos rurais de Manicoré, representam, em média, $26,32 \%$ do desflorestamento no período de 2000 a 2014, atingindo seu valor máximo em 2000, 102,4\%, mostrando que a maior parte do desflorestamento ocorre num cenário fora dos assentamentos (Figura 4).

As políticas federais que objetivam a mitigação do desflorestamento, em particular nos assentamentos rurais (BRASIL, 2001; BRASIL, 2004; BRASIL, 2012a; BRASIL, 2012b; BRASIL, 2013a) podem ter relação positiva com o desflorestamento nos assentamentos do município de Manicoré que decresceu desde 2000. O Código Florestal (BRASIL, 2012a) é considerado como a principal legislação ambiental vigente, o qual determina a manutenção de $80 \%$ de floresta em áreas de reserva legal. O percentual de uso e cobertura do solo nos PAEs do município de Manicoré 
está entre 0 a $15 \%$, entretanto no PA o valor ultrapassa $50 \%$ (Figura 5 ). Devido a ausência do mapeamento das áreas de reserva legal nos assentamentos rurais do município de Manicoré, há dificuldade de se discutir quanto sua legalidade perante o Código Florestal.

Figura 3 - Áreas desflorestadas em hectare e em percentual nos Projetos de Assentamentos Agroextrativistas (PAEs) e Projeto de Assentamento Federal (PA) de Manicoré/AM (2000 a 2014) e suas relações com o surgimento de políticas agrárias federais (BRASIL, 2001; BRASIL, 2004; BRASIL, 2006; BRASIL, 2012a; BRASIL, 2012b; BRASIL, 2013a).

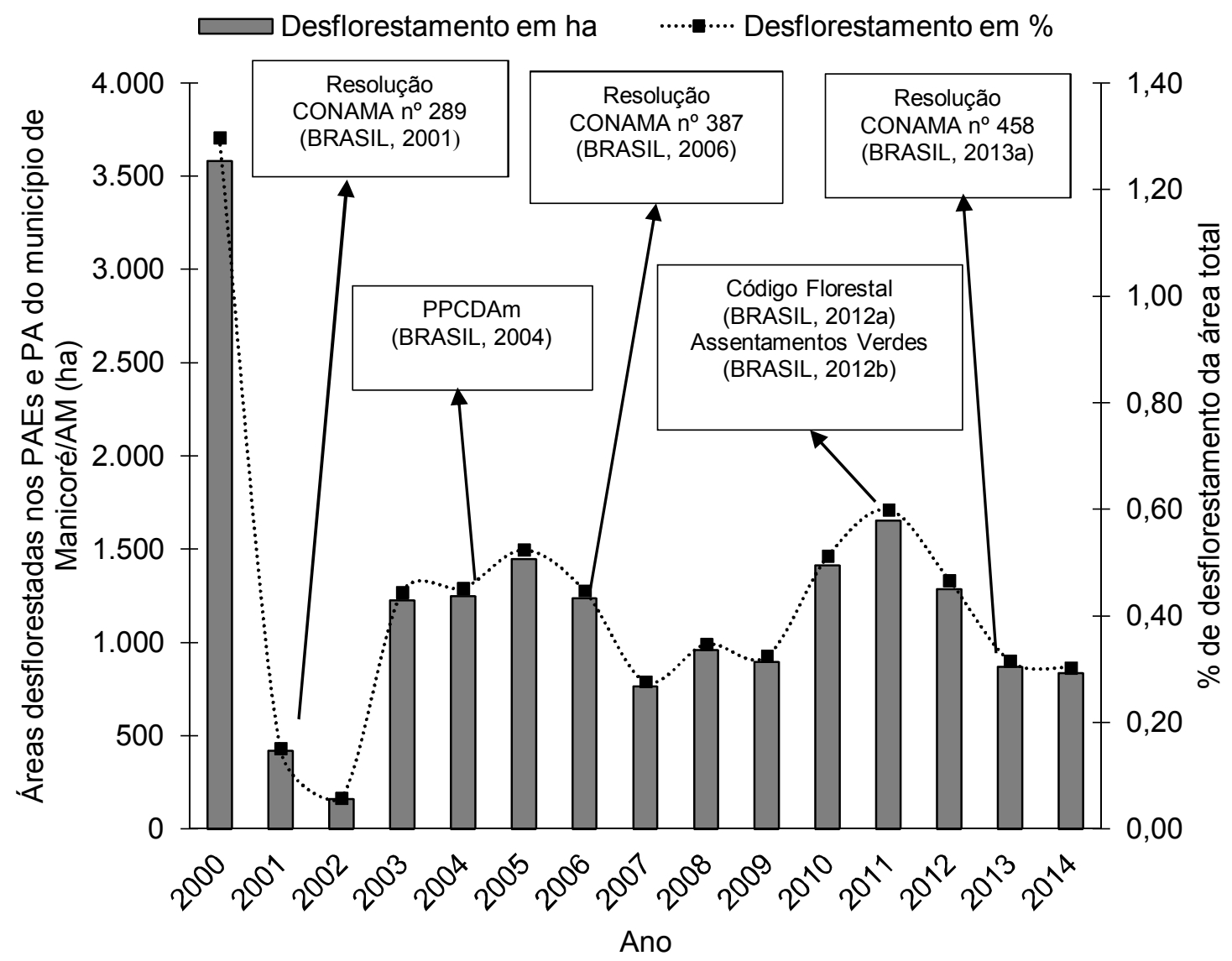

Base de dados: INPE (2003), com atualização permanente. 
Figura 4 - Participação dos Projetos de Assentamentos Agroextrativistas (PAEs) e Projeto de Assentamento Federal (PA) no desflorestamento de Manicoré/AM (2000 a 2014).

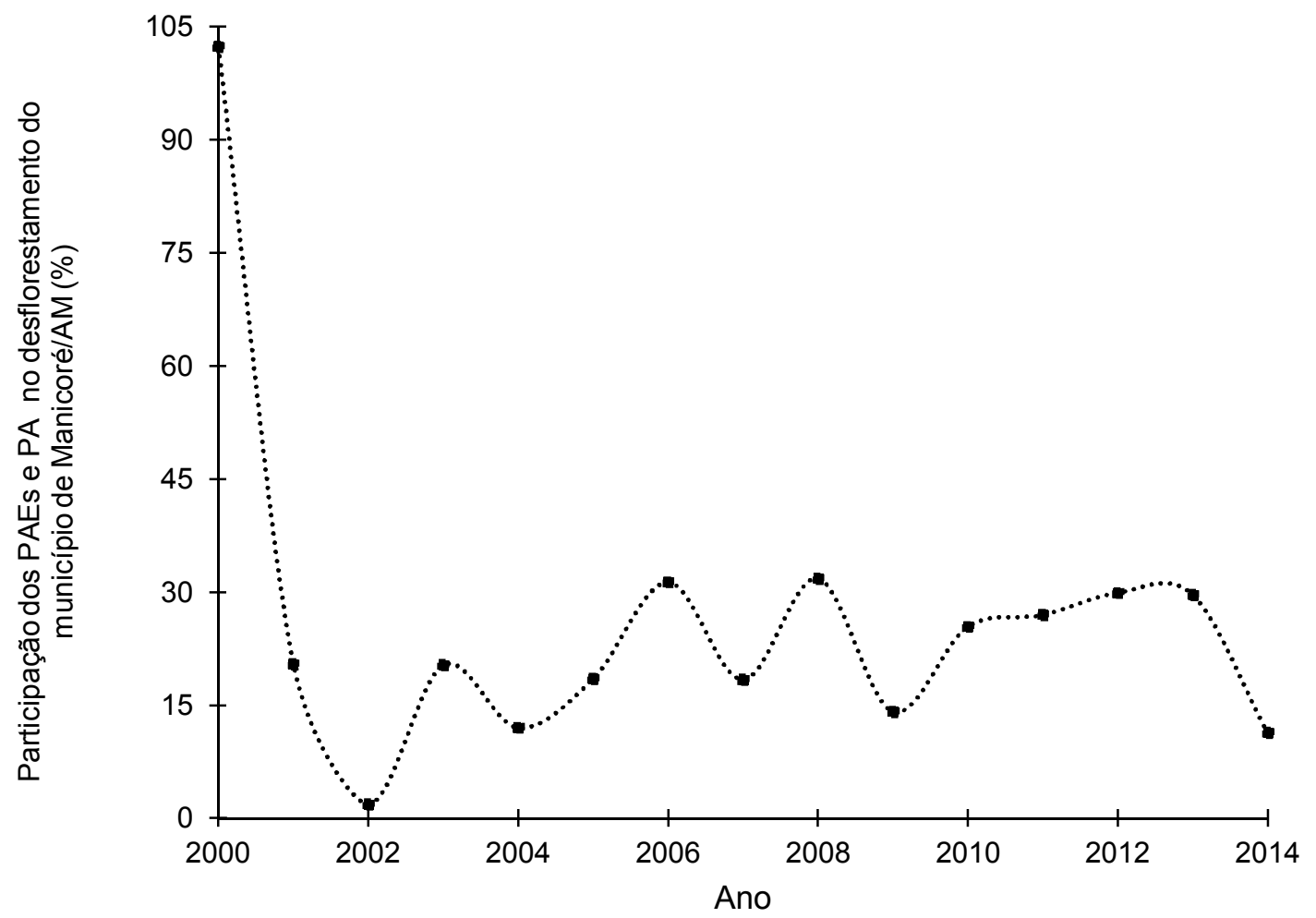

Base de dados: INPE (2003), com atualização permanente. 
Figura 5 - Percentual de uso e cobertura do solo nos Projetos de Assentamentos Extrativistas (PAEs) e Projeto de Assentamento Federal (PA) de Manicoré/AM até 2014.

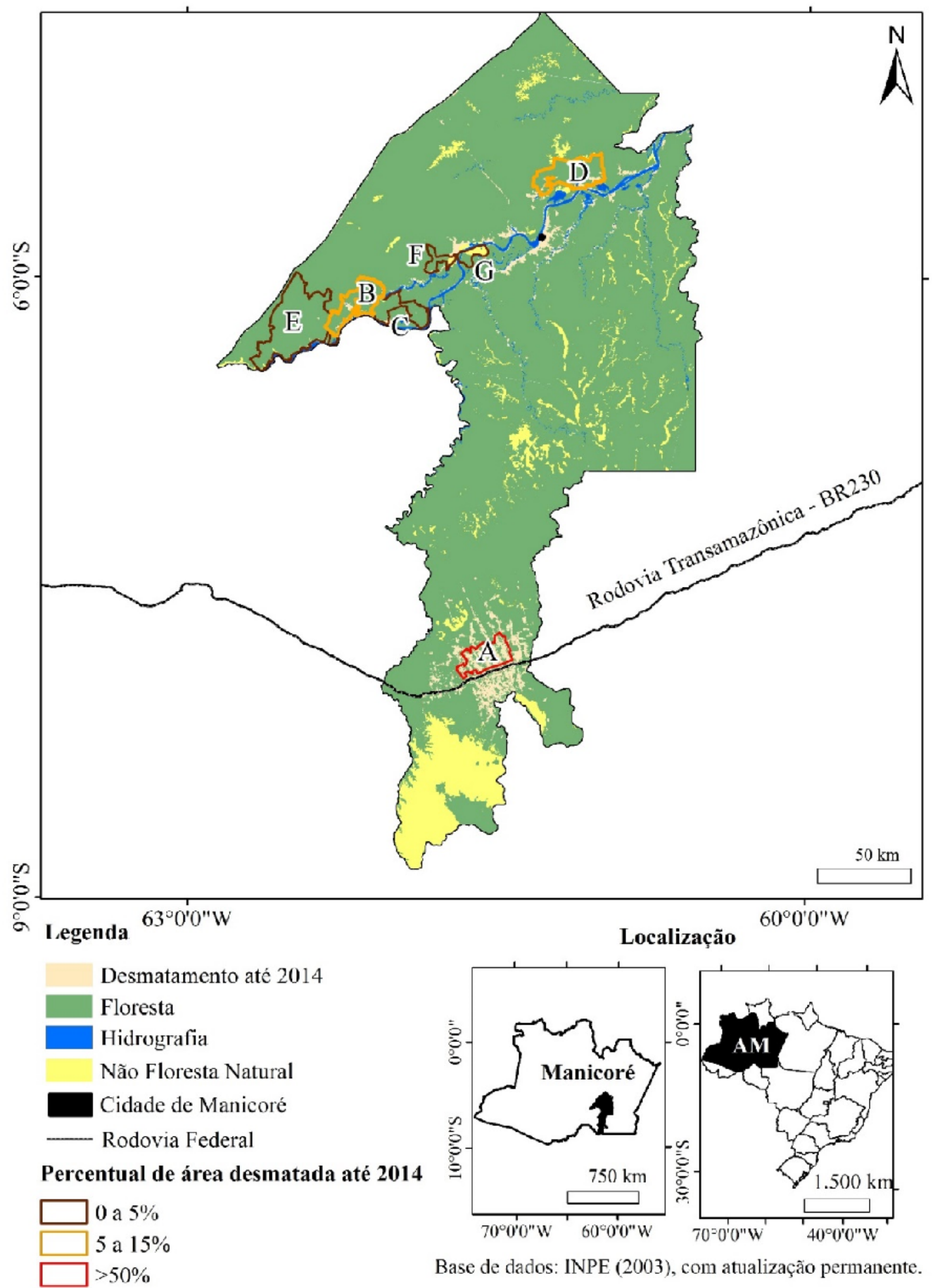

A - PA Matupi; B - PAE Baetas; C - PAE Fortaleza; D - PAE Jenipapos; E - PAE Lago do Acará; F - Matupiri; G - PAE Onças

Considerando que as políticas federais surgiram em épocas distintas a partir do ano de 2000, é importante analisar seus resultados nos anos seguintes. 


\section{COMPORTAMENTO DO DESFLORESTAMENTO NOS ASSENTAMENTOS RURAIS DE MANICORÉ/AM NO PERÍODO DE LANÇAMENTO DA RESOLUÇÃO CONAMA Nº 289}

A resolução CONAMA $n^{\circ} 289$ (BRASIL, 2001) que estabelece sobre o licenciamento ambiental em áreas de assentamentos rurais apresentou problemas em sua aplicação, pois no período de 2003 a 2005 foi realizado o licenciamento de apenas 718 assentamentos em todo o Brasil. Dentre os principais problemas apontados estão a necessidade de treinamento para sua aplicação, ausência de técnicos, estudos ambientais incompletos, e falta de áreas de reserva legal nos assentamentos de acordo com o relatório do Ministério do Meio Ambiente - MMA (MMA, 2005). Embora haja uma redução imediata no desflorestamento nos assentamentos rurais do município de Manicoré em 2002, no ano seguinte não houve continuidade (Figura 6).

Figura 6 - Reflexo da resolução CONAMA n. 289 (BRASIL, 2001) no desflorestamento dos assentamentos rurais de Manicoré/AM.

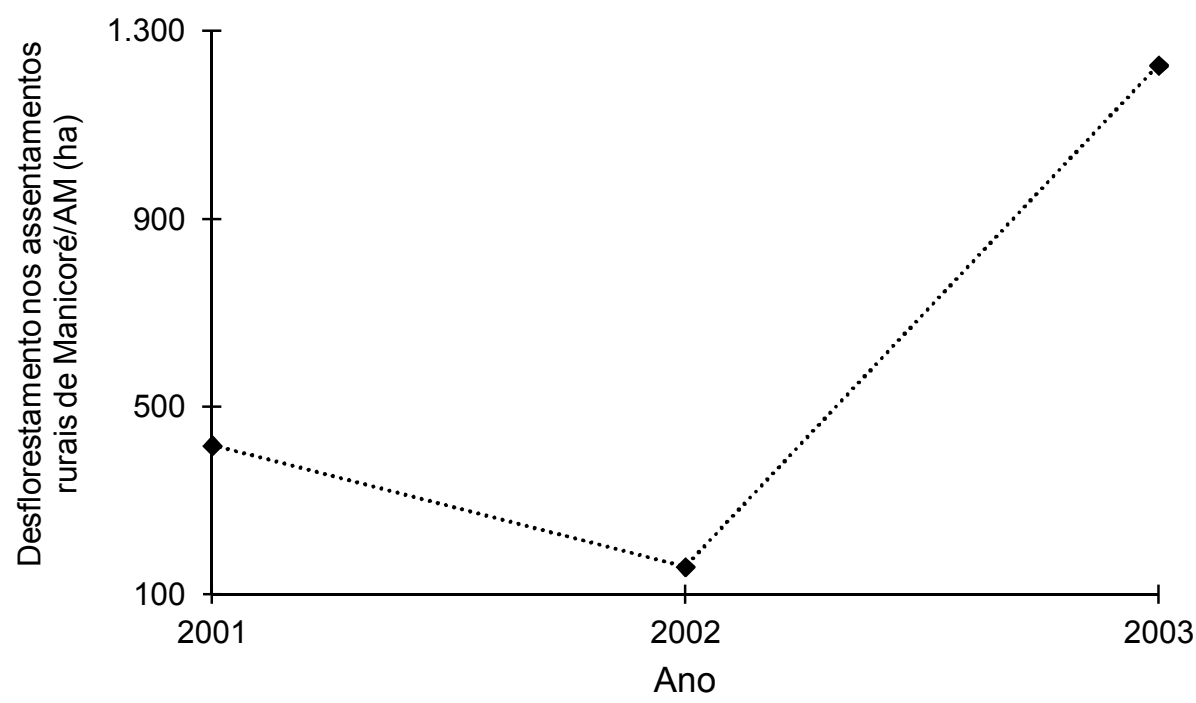

Base de dados: INPE (2003), com atualização permanente.

Ainda de acordo com o relatório do MMA embasado em informações do Instituto de Proteção Ambiental do Amazonas - IPAAM, o estado do Amazonas, esteve entre os mais contemplados com relação ao licenciamento em seus assentamentos rurais, uma vez que entre 2003 a 2005, havia 40 assentamentos em fase de Licença Prévia (LP) e outros 32 em Licença de Instalação Operação (LIO). Mesmo que a redução do desflorestamento não seja contínua, a resolução CONAMA n 289 (BRASIL, 2001) se apresenta de importância significativa, ainda que funcione apenas como medida educativa, pois estes instrumentos legislativos a nível estadual são escassos. 


\section{COMPORTAMENTO DO DESFLORESTAMENTO NOS} ASSENTAMENTOS RURAIS DE MANICORÉ/AM NO PERÍODO DE LANÇAMENTO DO PLANO DE AÇÃO PARA A PREVENÇÃO E CONTROLE DO DESFLORESTAMENTO NA AMAZÔNIA LEGAL PPCDAM

Durante a primeira fase do PPCDAm (2004-2008) o desflorestamento nos assentamentos de reforma agrária do município de Manicoré passou de 1.446 ha (2005) para 763 ha (2007), Figura 7. Neste mesmo período houve a primeira revogação da resolução CONAMA nº 289 (BRASIL, 2001) que se transformou na resolução CONAMA n 387 (BRASIL, 2006).

De acordo com o relatório da terceira fase do PPCDAm divulgado em Junho de 2013 (BRASIL, 2013b), o desflorestamento nos assentamentos de reforma agrária exibe proporções cada vez menores. Contudo, não na mesma velocidade que outras variáveis, o que resulta no crescimento de sua contribuição para o desflorestamento na Amazônia Legal. Sua participação no desflorestamento da região no período de 2000 a 2011 apresenta uma média de 19,1\%, próxima da contribuição dos assentamentos de Manicoré, os quais contribuem 26,3\% para o desflorestamento que ocorre no município.

Figura 7 - Reflexo do Plano de ação para a prevenção e o controle do desmatamento na Amazônia Legal - PPCDAm e da resolução CONAMA nº 387 (BRASIL, 2006) no desflorestamento dos assentamentos rurais de Manicoré/AM.

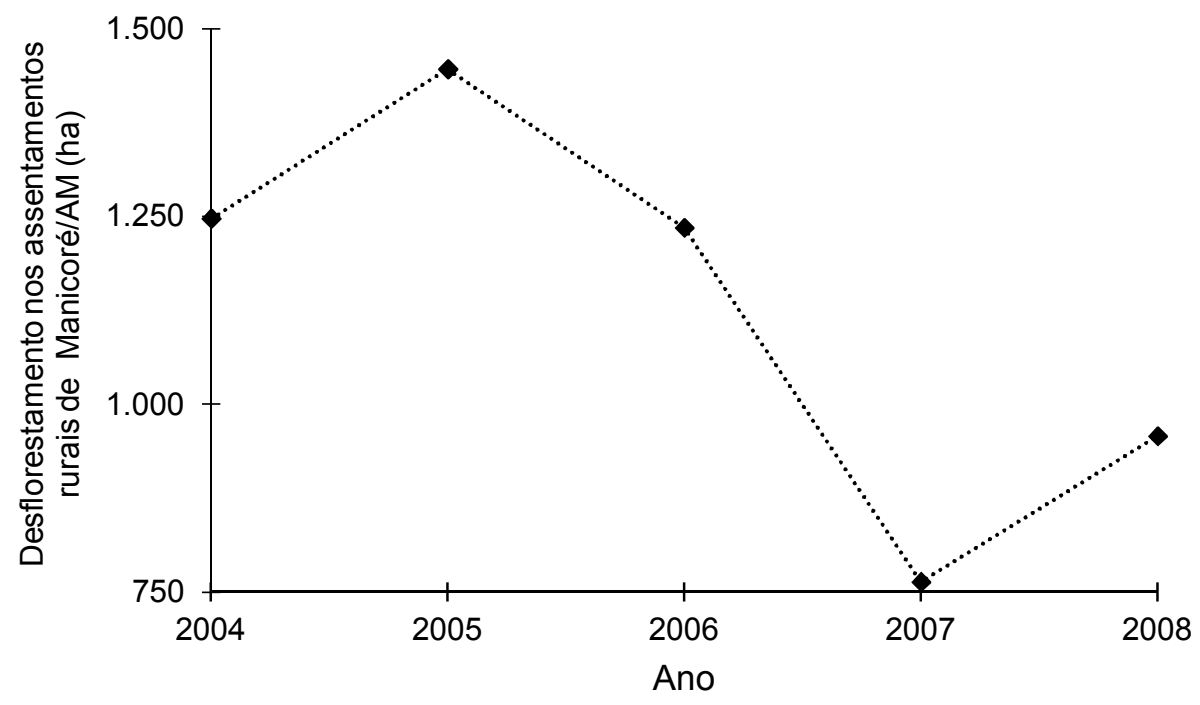

Base de dados: INPE (2003), com atualização permanente.

Outro resultado importante alcançado pelo PPCDAm a partir de 2004 foi o protocolo de 533 licenças ambientais em assentamentos rurais da Amazônia Legal em seus órgãos do meio ambiente, além do projeto de manejo buscando a recuperação de áreas de reserva legal, bem como a inserção de atividades sustentáveis (BRASIL, 2013b). Estes resultados podem ser variáveis explicativas para a redução do desflorestamento que ocorreu em 2007. 


\section{COMPORTAMENTO DO DESFLORESTAMENTO NOS} ASSENTAMENTOS RURAIS DE MANICORÉ/AM NO PERÍODO DE LANÇAMENTO DO NOVO CÓDIGO FLORESTAL E PROGRAMA DE ASSENTAMENTOS VERDES - PAV

Assim como ocorreu no período da resolução CONAMA n 289 (BRASIL, 2001) e no período de sua primeira revogação a qual transformou em resolução CONAMA n' 387 (BRASIL, 2006), o desflorestamento nos assentamentos rurais do município de Manicoré teve uma redução imediata após o lançamento do novo Código Florestal (BRASIL, 2012a), passando de 1.287 ha (2012) para 834 ha (2014), Figura 8.

Figura 8 - Reflexo do Código Florestal, Projeto de Assentamento Verde (PAV) e resolução CONAMA $n^{\circ}$. 458 (BRASIL, 2013a) no desflorestamento dos assentamentos rurais de Manicoré/AM.

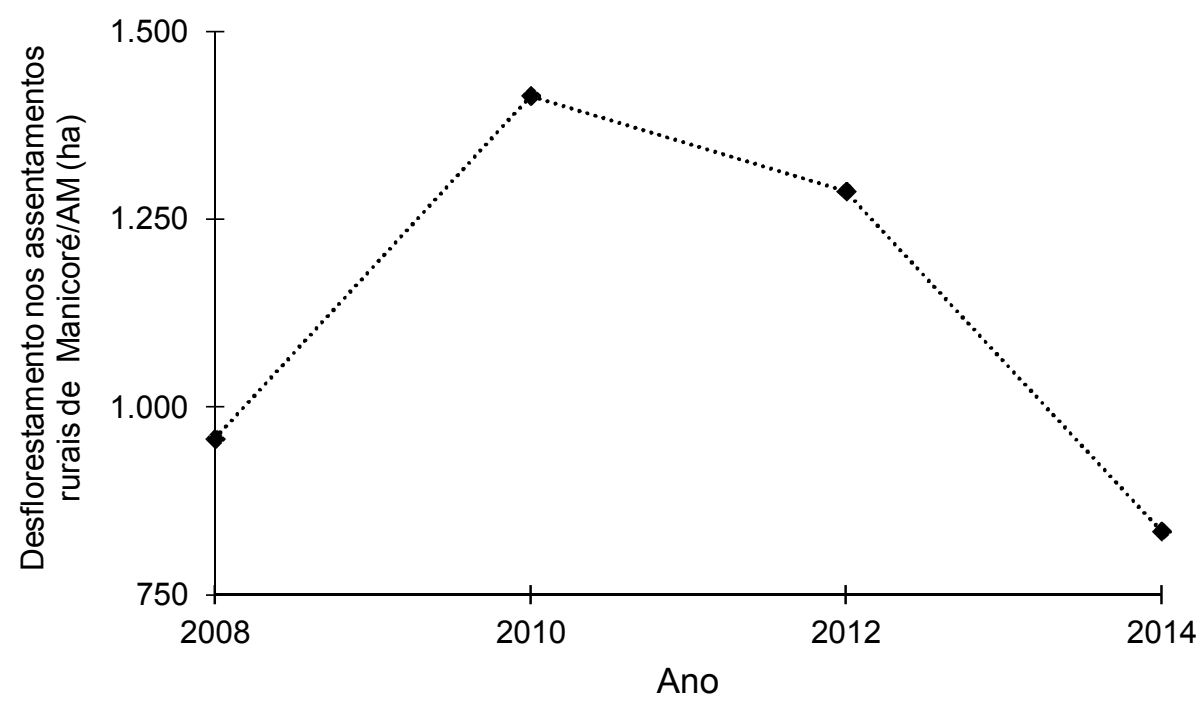

Base de dados: INPE (2003), com atualização permanente.

Além do lançamento do novo Código Florestal, outras medidas foram criadas paralelamente, bem como o Plano de Preservação, Combate e Alternativas ao Desmatamento llegal em Assentamentos da Amazônia, o Programa Assentamentos Verdes - (PAV) criado pelo INCRA, o qual já apresenta alguns resultados positivos como assistência técnica ao extrativismo atendendo 25 mil famílias e 27 mil bolsas verdes em 742 assentamentos. Em termos de desflorestamento, as superintendências regionais do Amazonas, Mato Grosso e Santarém registram queda entre 2013 e 2014. O Boletim de análise sobre o desflorestamento em assentamentos da Amazônia mostrou a ausência de registro de desflorestamento em $99 \%$ dos assentamentos analisados, considerando que em sua metodologia não foram considerados os assentamentos da época da colonização. Desta forma, pressupõe-se que o desflorestamento seja comum apenas em determinados projetos de assentamentos (INCRA, 2014).

No ano seguinte houve a revogação a resolução CONAMA n 387 (BRASIL, 2006) na resolução CONAMA n 458 (BRASIL, 2013a) que é medida mais recente das legislações neste sentido. Considerando que são legislações federais estes 
resultados sociais apresentados por todas as legislações podem ter reflexos positivos para o caso dos assentamentos rurais do município de Manicoré.

\section{CONCLUSÕES}

O município de Manicoré, assim como os municípios que apresentam as maiores taxas de desflorestamento no Amazonas, possui sua economia baseada em agropecuária, que é uma variável passível de ser correlacionada com o desflorestamento que ocorre dentro do município, já que de acordo com os dados da pesquisa, a maior parte do desflorestamento ocorre fora dos assentamentos rurais, que contribuem $26,3 \%$ para o desflorestamento do município. O Projeto de Assentamento Federal (PA) e os Projetos de Assentamentos Agroextrativistas (PAEs) do município de Manicoré tiveram uma taxa de desflorestamento média de 1.199 ha:ano $^{-1}$ no período de 2000 a 2014. O desflorestamento acumulado nos PAEs deste município representa valores de 0 a $15 \%$, pouco abaixo dos $20 \%$ delineados pelo Código Florestal, no entanto, o desflorestamento acumulado no PA do município ultrapassa $50 \%$ de sua área.

Embora o município de Manicoré contenha um assentamento tradicional, assim como o município de Humaitá, também é composto em sua maioria por assentamentos extrativistas ao longo da margem de rios, impedindo a chegada de outras variáveis de desflorestamento, como posseiros.

O surgimento da resolução CONAMA n 289 (BRASIL, 2001) a sua revogação com a resolução CONAMA 387 (BRASIL, 2006) e a instituição do novo Código Florestal (BRASIL, 2012a) resultaram no decrescimento imediato do desflorestamento nos assentamentos do município de Manicoré no ano seguinte que, no entanto, não teve uma continuidade. Isto reforça a tese de que medidas potencialmente punitivas não tenham gerado resultados duradouros esperados, e que investimentos em programas de educação ambiental que possam proporcionar melhoria na formação dos assentados se mostra como uma possível alternativa para quebrar o paradigma que os faz desacreditar na rentabilidade da produção sustentável.

\section{REFERÊNCIAS}

ALENCAR, A.; NEPSTAD, D.; McGRATH, D.; MOUTINHO, P.; PACHECO, P.; DIAZ, M. D. C. V.; SOARES-FILHO, B. Desmatamento na Amazônia: Indo além da "Emergência Crônica". Belém: Instituto de Pesquisa Ambiental da Amazônia, 2004. 85 p.

ALENCAR, A.; PEREIRA, C.; CASTRO, I.; CARDOSO, A.; SOUZA, L.; COSTA, R.; BENTES, A. J.; STELLA, O.; AZEVEDO, A.; GOMES, J.; NOVAES, R.

Desmatamento nos assentamentos da Amazônia: histórico, tendências e oportunidades. Brasília: IPAM, 2016. 93p.

AMAZONAS - SECRETARIA DE ESTADO DO MEIO AMBIENTE. Plano estadual de prevenção e combate ao desmatamento no Amazonas. Manaus, 2008, 54p. 
BRANDÃO JÚNIOR, A.; SOUZA JÚNIOR, C. Desmatamento nos assentamentos de reforma agrária na Amazônia, O Estado da Amazônia, Imazon, n. 7, p. 1-4, 2006. Disponível em: <http://www.imazon.org.br>. Acesso em: 20 jun. 2016

BRASIL. Lei n 6.938, de 31 de agosto de 1981. Dispõe sobre a Política Nacional do Meio Ambiente, seus fins e mecanismo de formulação e aplicação. Brasília, 1981. Disponível em: <http://www.planalto.gov.br/ccivil_03/leis/L6938.htm>. Acesso em: 13 marc. 2017.

BRASIL. Ministério do Meio Ambiente, Conselho Nacional de Meio Ambiente, CONAMA. Resolução CONAMA n. 289, de 25 de Outubro de 2001. Disponível em: <http://www.mma.gov.br>. Acesso em: 22 set. 2016.

BRASIL. Plano de ação para a prevenção e controle do desmatamento na Amazônia Legal. Brasília, 2004. 156p. Disponível em:

<http://www.greenpeace.org>. Acesso em: 22 set. 2016.

BRASIL. Ministério do Meio Ambiente, Conselho Nacional de Meio Ambiente, CONAMA. Resolução CONAMA n. 387, de 27 de Dezembro de 2006. Disponível em: <http://www.mma.gov.br>. Acesso em: 22 set. 2016.

BRASIL. Lei n 12.651 de 25 de maio de 2012a. Institui o Novo Código Florestal Brasileiro. Brasília: DOU de 28/5/2012. Disponível em: <http://www.planalto.gov.br>. Acesso em: 22 set. 2016

BRASIL. Portaria $\mathrm{n}^{\circ} 716$ de 28 de novembro de 2012b. Institui o Programa de Prevenção, Combate e Alternativas ao Desmatamento llegal em Assentamentos da Amazônia, PPCADI-Amazônia, denominado "Programa Assentamentos Verdes". DOU de 28/11/2012.

BRASIL. Ministério do Meio Ambiente, Conselho Nacional de Meio Ambiente, CONAMA. Resolução CONAMA nº 458, de 16 de julho de 2013a. Disponível em: <http://www.mma.gov.br>. Acesso em: 22 set. 2016.

BRASIL. Ministério do Meio Ambiente. Plano de ação para a prevenção e controle do desmatamento na Amazônia Legal (PPCDAm): $3^{a}$ fase (2012-2015) pelo uso sustentável da Floresta. Brasília: 2013b. Disponível em:

<http://www.amazonfund.gov.br>. Acesso em: 09 mar. 2017.

CASTELO, T. B. Legislação Florestal Brasileira e Políticas de governo de combate ao desmatamento na Amazônia Legal. Ambiente \& Sociedade, v. XVIII, n. 4, p. 221-242, out/dez, 2015.

FEARNSIDE, P. M. Desmatamento na Amazônia Brasileira: história, índices e consequências. Megadiversidade, v. 1, n.1, 2005.

FONSECA, A.; SOUZA JÚNIOR, C.; VERÍSSIMO, A. Boletim do desmatamento da Amazônia Legal (janeiro de 2016) SAD. Belém: Imazon, 2016. 10p. Disponível em: <http://www.imazon.org.br>. Acesso em: 22 set. 2016. 
IBGE - Instituto Brasileiro de Geografia e Estatística. Infográficos: despesas e receitas orçamentárias e PIB, 2017. Disponível em: <http://www.ibge.gov.br>. Acesso em: 28 fev. 2017.

INCRA - Instituto Nacional de Colonização e Reforma Agrária. Relação de beneficiários do programa nacional de reforma agrária, 2014. Disponível em: <http://www.incra.gov.br>. Acesso em: 12 nov. 2016.

INCRA - Instituto Nacional de Colonização e Reforma Agrária. Acervos fundiários, 2016. Disponível em: <http://www.incra.gov.br>. Acesso em: 20 jan. 2016.

INPE - Instituto Nacional de Pesquisas Espaciais. Projeto PRODES Digital: Programa de cálculo do desflorestamento da Amazônia, 2003, com atualização permanente. Disponível em: <http://www.obt.inpe.br/prodes/index.php>. Acesso em: 01 out. 2016.

MMA - Ministério do Meio Ambiente. Relatório sobre a aplicação da resolução CONAMA 289/2001 - Diretrizes para o licenciamento ambiental dos projetos de reforma agrária. 2005. Disponível em: <http://www.mma.gov.br>. Acesso em: 20 fev. 2017.

OLIVEIRA, L. C. Legislação Ambiental e a criação de assentamentos rurais: Os dilemas dos projetos de assentamento Emiliano Zapata e Flávia Nunes, Uberlândia-MG. 2016. 115p. Dissertação (Mestrado em Extensão Rural) Universidade Federal de Viçosa, Viçosa/MG, 2016.

SILVA, V. V. Impactos das atividades produtivas na dinâmica da paisagem do assentamento Matupi, estado do Amazonas. 2012.117p. Tese (Doutorado em Ecologia Aplicada) - Escola Superior de Agricultura Luiz de Queiroz, Universidade de São Paulo, Piracicaba/SP, 2012.

STRECK, M. T.; ESSI, L. Áreas de preservação permanente e reserva legal: experiência em educação ambiental envolvendo famílias de produtores rurais, Revista do Centro do Ciências Naturais e Exatas, v. 14, n. 14, set. 2013. 